\title{
Comparative Study of the Conventional Parasitological Methods for the Detection of T. evansi in Buffaloes
}

\author{
Rashmi Sharma ${ }^{1}$, Nidhi S. Choudhary ${ }^{1 *}$, R.K. Bagherwal ${ }^{1}$, Vivek Agrawal ${ }^{2}$, \\ Hemant Mehta ${ }^{1}$ and Arun Mourya ${ }^{1}$ \\ ${ }^{1}$ Department of Veterinary Medicine, College of Veterinary Science and A.H., Mhow (M.P.), INDIA \\ ${ }^{2}$ Department of Parasitology, College of Veterinary Science and A.H. Mhow (MP), INDIA \\ *Corresponding author: NS Choudhary; E-mail: drnidhichoudhary2002@gmail.com
}

Received: 05 May, 2021

Revised: 08 July, 2021

Accepted: 12 July, 2021

\begin{abstract}
In this study four conventional parasitological methods like Wet blood film (WBF), thin and thick blood smear and Buffy coat technique (BCT) were compared for diagnostic sensitivity of Trypanosoma evansi in naturally infected buffaloes. Out of 250 field blood samples collected from different places of Indore and Ratlam district of M.P., $1.2 \%$ were found positive by wet blood film, $4.4 \%$ by thin blood smear, $9.2 \%$ by thick blood smear and $14.8 \%$ by buffy coat technique for $T$. evansi. The sensitivity and specificity of the all methods were analyzed and it was observed that BCT is more sensitive than the other conventional methods of examination.

HIGHLIGHTS

(0 Conventional parasitological methods were compared for diagnostic sensitivity of Trypanosoma evansi in naturally infected buffaloes.

(0 Buffy coat technique is more sensitive than the other conventional methods of examination.
\end{abstract}

Keywords: Trypanosoma evansi, Buffalo, Wet blood film, Blood smear and Buffy coat technique

Trypanosomosis commonly known as "Surra" caused by Trypanosoma evansi is most widely distributed in Asia, Africa and Central and South America affecting domesticated livestock Konnai et al. (2009). This chronic disease caused by the first pathogenic trypanosome $T$. evansi was identified by Griffith Evans in 1880 from the blood of Indian horses and camels. T. evansi being the most commonly occurring species of trypanosomes Singh and Singla (2013). Recurrent episodes of fever and parasitaemia occur during the course of disease. Vectors involved in the spread of disease are Muscoid and Tabanid biting flies Shahzad et al. (2012). The major hindrance of diagnosis of Surra is due to its cryptic nature and not revealing of any pathognomic clinical symptoms (Dia et al., 1997). To overcome the limitation of diagnosis, concentration methods of parasites are available like Buffy coat technique by which sensitivity can be increased approximately upto 10 times (Reid et al., 2001) otherwise the sensitivity of giemsa stained thin blood smear are $\sim 10^{5}$ trypanosomes $\mathrm{ml}^{-1}$ of blood (Paris et al., 1982).

Trypanosomosis is endemic in India. Due to lack of confirmatory diagnosis, failure of treatment and other direct and indirect losses caused by trypanosomosis is very high and it was estimated Indian Rupee (INR) 44,740 million annually in 2017 which are likely to be substantially greater. In buffaloes, total economic losses due to trypanosomosis was (INR 11864.83 million) comprising of direct visible losses (INR 6996.67 million) and invisible

How to cite this article: Sharma, R., Choudhary, N.S., Bagherwal, R.K., Agrawal, V., Mehta, H. and Mourya, A. (2021). Comparative Study of the Conventional Parasitological Methods for the Detection of T. evansi in Buffaloes. J. Anim. Res., 11(04): 729-732.

Source of Support: None; Conflict of Interest: None 
losses (INR 4868.16 million). Out of total economic losses due to trypanosomiosis, INR 112.78 million was due to treatment costs. Trypanosomosis in buffaloes contributed $26.77 \%$ of total estimated loss (Kumar et al., 2017). Outbreak of Trypanosomosis in ruminants have been reported from various parts of country (Kumar et al., 2012; Shyma et al., 2012) and mortality rate in cattle and buffaloes ranging from 20 to $90 \%$ in Indian subcontinent (Gill, 1991; Kumar et al., 2012). The objective of study was to compare the sensitivity and specificity of various conventional parasitological diagnostic methods for the diagnosis of trypanosomosis.

\section{MATERIALS AND METHODS}

Total 250 buffaloes were screened (125 animals from each district) and clinically examined with special attention to signs related to trypansoma infection in and around Indore and Ratlam districts over the period of 12 months from June 2017 to May 2018. Blood samples from 250 buffaloes from different places of Indore and Ratlam districts of M.P. were collected aseptically from ear vein by sterile sharp needle in clean and dry test tube kept at $4^{\circ} \mathrm{C}$ and examined within 12 hours after collection as viability of trypanosomes is limited in time, by the extended interval between sample collection and parasite detection. Method of Rathore and Sengar (2005) was followed for screening of trypanosoma infection by Wet blood film examination, Giemsa's stained thin and thick blood smear method of Murray et al. (1977) was followed for detection of trypanosoma infection by Buffy coat technique (BCT).

\section{RESULTS AND DISCUSSION}

The efficacy of various conventional parasitological methods were as follows in decreasing order: Buffy Coat method $(14.8 \%)>$ Giemsa stained thick blood smear $(9.2 \%)>$ Giemsa stained thin blood smear $(4.4 \%)>$ Wet blood film (1.2\%) (Table 1).

These findings are in corroborated with results (buffy coat technique $>$ thick film $>$ thin film $>$ wet film) of Paris et al. (1982). T. evansi due to its cryptic nature and intermittent nature of parasitaemia, it is frequently absent from peripheral blood (Kendrick, 1968) and enrichment methods like buffy coat technique is useful to diagnose the low parasitaemia.
Considering BCT as gold standard, the sensitivity and specificity of the other conventional methods were analyzed by $2 \times 2$ contingency table (Table 2,3 and 4 ). Sensitivity and specificity of WBF, $8.12 \%$ and $100 \%$, thin blood smear $29.73 \%$ and $100 \%$ and thick blood smear $62.16 \%$ and $100 \%$ were reported, respectively and it was observed that $\mathrm{BCT}$ is more sensitive than the other conventional methods of examination, these results are in close relation with other researchers Jaiswal et al. (2015), Singh et al. (2017) and Carlos et al. (1990).

The buffy coat technique (Fig. 1) detected more number of cases of $T$. evansi infection compared with giemsa stained blood smears (Fig. 2 and 3) examination. Level of parasitaemia is very low in mild clinical or subclinical carrier infection and therefore concentration method like buffy coat technique as recommended by OIE, 2000 is low cost alternative method to diagnose the cryptic nature of surra. Similarly Dwivedi (2004) also emphasized the use of buffy coat technique for diagnosis of subclinical or carrier cases of T. evansi in bovines.

Table 1: Comparative diagnostic evaluation of trypanosomosis by various methods

\begin{tabular}{lllll}
\hline Methods & $\begin{array}{l}\text { Animals } \\
\text { screened }\end{array}$ & Positive & Negative & Percentage \\
\hline WBF & 250 & 3 & 247 & 1.2 \\
$\begin{array}{l}\text { Thin blood } \\
\text { smear }\end{array}$ & 250 & 11 & 239 & 4.4 \\
$\begin{array}{l}\text { Thick blood } \\
\text { smear }\end{array}$ & 250 & 23 & 227 & 9.2 \\
BCT & 250 & 37 & 213 & 14.8 \\
\hline
\end{tabular}

Table 2: Contingency table for WBF and BCT for Trypanosoma evansi

\begin{tabular}{|c|c|c|c|c|}
\hline \multirow[t]{2}{*}{ WBF } & & \multicolumn{2}{|c|}{ BCT } & \multirow{2}{*}{ Total } \\
\hline & & Positive & Negative & \\
\hline & Positive & $3^{\mathrm{a}}$ & $0^{\mathrm{b}}$ & 3 \\
\hline & Negative & $34^{\mathrm{c}}$ & $213^{\mathrm{d}}$ & 247 \\
\hline Total & & 37 & 213 & 250 \\
\hline
\end{tabular}

Sensitivity of $\mathrm{WBF}=8.12 \%$

Specificity of $\mathrm{WBF}=100$ 
Table 3: Contingency table for Thin Blood smear and BCT for Trypanosoma evansi

\begin{tabular}{llllll}
\hline \multirow{2}{*}{$\begin{array}{l}\text { Thin } \\
\text { blood } \\
\text { smear }\end{array}$} & \multicolumn{3}{c}{ BCT } & \multirow{2}{*}{ Total } \\
\cline { 2 - 5 } & Positive & $11^{\mathrm{a}}$ & $0^{\mathrm{b}}$ & 11 & \\
& Negative & $26^{\mathrm{c}}$ & $213^{\mathrm{d}}$ & 239 \\
\hline Total & & 37 & 213 & 250 \\
\hline
\end{tabular}

Sensitivity of Thin Blood smear $=29.73 \%$; Specificity of Thin Blood smear $=100 \%$.

Table 4: Contingency table for Thick blood smear and BCT for Trypanosoma evansi

\begin{tabular}{|c|c|c|c|c|}
\hline \multirow{3}{*}{$\begin{array}{l}\text { Thick } \\
\text { blood } \\
\text { smear }\end{array}$} & \multirow[b]{3}{*}{ Positive } & \multicolumn{2}{|r|}{ BCT } & \multirow{2}{*}{ Total } \\
\hline & & Positive & Negative & \\
\hline & & $23^{\mathrm{a}}$ & $0^{\mathrm{b}}$ & 23 \\
\hline & Negative & $14^{\mathrm{c}}$ & $213^{\mathrm{d}}$ & 227 \\
\hline Total & & 37 & 213 & 250 \\
\hline
\end{tabular}

Sensitivity of Thick Blood smear $=62.16 \%$; Specificity of Thick Blood smear $=100 \%$.
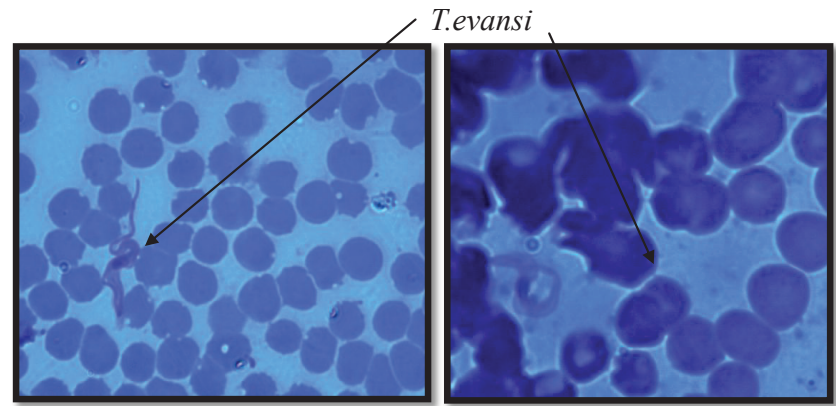

Fig. 1: Photomicrograph Fig. 2: Photomicrograph showing $T$. evansi in thin showing $T$. evansi in thick blood smear under oil blood smear under oil emersion emersion

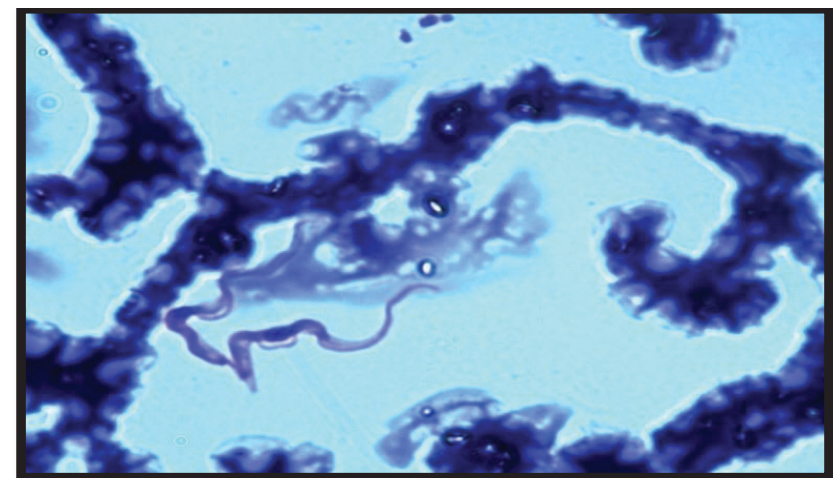

Fig. 3: Photomicrograph showing T. evansi in BCT under oil emersion

\section{REFERENCES}

Carlos, M.M., Orlando, A.M. and Juan, P.R. 1990. Comparison between six parasitological methods for diagnosis of Trypanosoma evansi in the subtropical area of Argentina. Vet. Parasitol., 36: 141-146.

Dia, M.L., Van, M.N., Magnus, E., Luckins, A.G., Diop, C., Thiam, A., Jacquiet, P. and Hamers, R. 1997. Evaluation de 4 tests de diagnostic: Frottis sanguins, CATT, IFI et ELISA$\mathrm{Ag}$ dans l'étude de l'épidémiologie de latrypanosomose cameline à T. evansi en Mauritanie. Rev. Elev. Med. Vet. Pays. Trop., 50(1): 29-36.

Dwivedi, S.K. 2004. Trypanosomiasis - Recent advances in diagnosis and therapy. Indian J. Vet. Pract., pp. 41-47.

Gill, B.S. 1991. Trypanosomes and Trypanosomiasis of Indian Livestock. $1^{\text {st }}$ Edn, Indian Council of Agricultural Research, New Delhi.

Jaiswal, A.K., Sudan, V., Neha and Verma, A.K. 2015. Insight into Trypanosomiasis in animals: Various approaches for its Diagnosis, treatment and control: A Review. Asian J. Anim. Sci., 9: 172-186.

Kendrick, K.R. 1968. The diagnosis of Trypanosomosis of livestock: A review of current techniques. Vet. Bull., 38: 191197.

Konnai, S., Mekata, H., Mingala, C.N., Abes, N.S., Gutierrez, C.A., Herrera, J.R.V., Dargantes, A.P., Witola, W.H., Cruz, L.C., Inoue, N. and Onuma, M. 2009. Development and application of a quantitative real-time PCR for the diagnosis of Surra in water buffaloes. Infection, Genetics and Evolution, 9: $449-452$

Kumar, H., Gupta, M.P., Sidhu, P.K., Mahajan, V., Bal, M.S., Kaur K., Ashuma, Verma, S. and Singla, L.D. 2012. An outbreak of acute Trypanosoma evansi infection in crossbred cattle in Punjab, India. J. Appl. Anim. Res., 40(03): 256-259.

Kumar, R., Jain, S., Kumar, S., Sethi, K., Kumar, S., and Tripathi, B.N. 2017. Impact estimation of animal trypanosomosis (surra) on livestock productivity in India using simulation model: Current and future perspective. Vet. Parasitol.: Regional Stud. Report., 10: 1-12.

Murray, M., Murray, P.K. and McIntyre, W.I.M. 1977. An improved parasitological technique for the diagnosis of African trypanosomosis. Transactions of the Royal Society of Tropical Medicine and Hygiene, 71: 325-326.

Office International des Epizooties/World Organization for Animal Health, (OIE). 2000. Manual of Standard diagnostic tests and vaccines.

Paris, J., Murray, M. and McOdimba, F. 1982. A comparative evaluation of the parasitological techniques currently available for the diagnosis of African trypanosomiasis in cattle. Acta Trop., 39: 307-316. 
Rathore, V.S. and Sengar, Y.S. 2005. Diagnostic Parasitology, Pointer Publishers, Jaipur, pp. 75-79.

Reid, S.A., Husein, A. and Compeman, P.D. 2001. Evaluation and improvement of parasitological tests for Trypanosoma evansi infection. Vet. Parasitol., 102(4): 291-297.

Shahzad,W., Munir, R., Khan, M.S., Ahmad, M.U.D. and Iqbal, M. 2012. Molecular Diagnosis and Chemotherapy of Trypanosoma evansi in Nili-Ravi Buffaloes at District Okara (Pakistan). The J. Anim. Plant Sci., 22: 212-216.

Shyma, K.P., Gupta S.K., Singh, A., Chaudhary, S.S. and Gupta, J.P. 2012. Efficiency of monoclonal antibody based latex agglutination test in detecting Trypanosoma evansi under field conditions for improving the productivity in buffaloes. Buffalo Bull., 32(3): 163-172.
Singh, A.P., Tripathi, A.K., Singh, A., Srivastava, A. and Singh, R. 2017. Assessment of diagnostic efficacy of various methods in detection of Trypanosoma evansi infection in buffaloes. Buffalo Bull., 36:147-153.

Singh, V. and Singla, L.D. 2013. Trypanosomosis (Surra) in Livestock. Research Gate, pp. 305-330. 